\title{
Ensinando sobre Representação de Imagens: Experiência no Projeto Computação Plugada com o Aplicativo Pixel
}

\author{
Larrysa Figueiredo \\ UFPB - Campus IV \\ Rio Tinto, PB, Brasil \\ larrysa.mirelly@dcx.ufpb.br \\ Josinaldo Pontes Júnior \\ UFPB - Campus IV \\ Rio Tinto, PB, Brasil \\ josinaldo.pontes@dcx.ufpb.br
}

\author{
Matheus Barbosa \\ CIn - UFPE \\ Recife, PE, Brasil \\ matheus.barbosa@dcx.ufpb.br
Ayla Dantas Rebouças
UFPB - Campus IV
Rio Tinto, PB, Brasil
ayla@dcx.ufpb.br

\author{
Emanoel Silva \\ UFPB - Campus IV \\ Rio Tinto, PB, Brasil \\ emanoel.silva@dcx.ufpb.br \\ Ivonildo Pereira Neto \\ CIn - UFPE \\ Recife, PE, Brasil \\ ivonildo.pereira@dcx.ufpb.br
}

Neste trabalho apresentamos o aplicativo "Pixel", que foi construído com base na atividade desplugada "Colorindo com Números - Representação de Imagens” do livro de Bell et al. (2011) [1]. O aplicativo apresenta quatro níveis. Espera-se que ao longo de cada um, o usuário possa aprender sobre representação de imagens por meio de informações e atividades para exercitar os conteúdos apresentados. Mostra-se, por exemplo, como se pode através de uma matriz representar cada pixel de uma imagem e a importância da compactação de dados.

Uma versão de desenvolvimento do aplicativo e ainda em testes pode ser baixada a partir do site do projeto Computação Plugada (https://sites.google.com/view/computacaoplugada/aplicativos/cppixel). Espera-se que o aplicativo possa ser utilizado em sala de aula e também em outros espaços. Estudos visando seu aprimoramento e avaliação em sala de aula estão sendo desenvolvidos atualmente.

É importante destacar que no projeto "Computação Plugada" tem-se buscado construir aplicativos com base em atividades de computação desplugada como forma de estimular o pensamento computacional [5] explorando dispositivos móveis. Em estudos iniciais com o primeiro aplicativo desenvolvido no projeto, o Computação Plugada - Binários [4], percebeu-se o quanto jovens se sentiram engajados ao utilizar o aplicativo e se mostraram interessados no processo de resolução de problemas ali propostos [3].

Durante o desenvolvimento do trabalho de Oliveira et al. [3], também se observou que professores que já tinham utilizado em sala de aula atividades desplugadas e que avaliaram aquele aplicativo, acharam a abordagem promissora. Um outro trabalho relacionado foi o de Gomes Neto [2], onde foi desenvolvida e avaliada uma nova interface do aplicativo sobre números binários tendo como foco o público infantil de crianças de 7 a 9 anos.

O aplicativo Pixel, que apresentamos aqui, foi desenvolvido considerando o que foi aprendido nestes trabalhos e visando tornar acessível a diferentes pessoas, mas principalmente crianças e jovens, o conhecimento sobre a representação de imagens em Pixels.

Fica permitido ao(s) autor(es) ou a terceiros a reprodução ou distribuição, em parte ou no todo, do material extraído dessa obra, de forma verbatim, adaptada ou remixada, bem como a criação ou produção a partir do conteúdo dessa obra, para fins não comerciais, desde que sejam atribuídos os devidos créditos à criação original, sob os termos da licença CC BY-NC 4.0.

EduComp'21, Abril 26-30, 2021, Jataí, Goiás, Brasil (On-line)

(c) 2021 Copyright mantido pelo(s) autor(es). Direitos de publicação licenciados à Sociedade Brasileira de Computação (SBC).
Na Figura 1 estão ilustradas algumas das telas do aplicativo. A primeira tela é a tela inicial, seguida pela tela de níveis. Uma outra tela apresentada é uma tela com uma atividade de múltipla escolha sobre o conteúdo relacionado ao funcionamento de uma máquina de fax. A quarta tela apresentada mostra uma atividade onde o usuário pode pintar os pixels de preto ou branco de acordo com a codificação apresentada, e descobrir qual a letra a que se refere a imagem. Por fim, mostra-se também uma tela de feedback sobre o nível para buscar motivar os estudantes e mostrar-lhes o que esperamos que tenham aprendido com as atividades propostas.

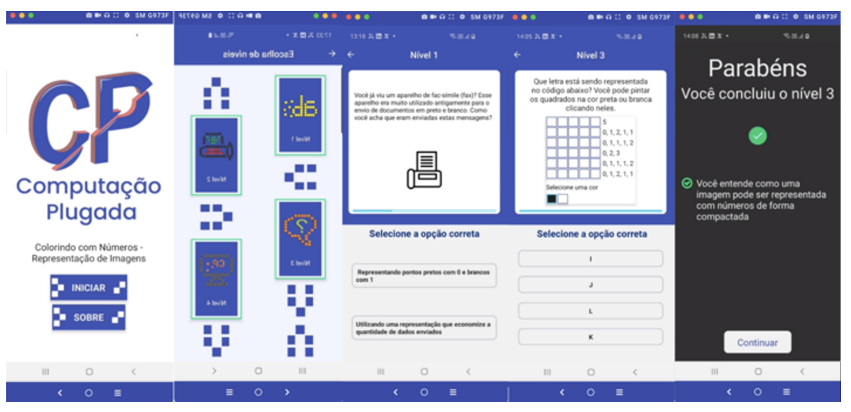

Figura 1: Telas do aplicativo Pixel

Em alguns níveis reforça-se a importância de buscar comprimir dados como forma de usar menos espaço para guardar imagens nos dispositivos ou para transmitir imagens na rede de forma mais rápida. Uma das técnicas de compressão apresentadas é o método 'run-length coding' e que é também explorado na atividade desplugada do livro de Bell et al. (2011) [1].

Acreditamos que a abordagem de criar aplicativos com base em atividades da computação desplugada pode tornar mais fácil a aplicação destas atividades por professores e pode aproximar mais crianças e jovens da Ciência da Computação, disseminando ainda mais essas atividades. Como trabalhos futuros, pretendemos fazer melhorias no aplicativo Pixel e realizar avaliações com estudantes da educação básica e com professores explorando este e outros aplicativos que estão sendo projetados e que seguem a mesma filosofia. 


\section{AGRADECIMENTOS}

Agradecemos à Pró-reitoria de Extensão da UFPB que nos apoiou na realização do Projeto Computação Plugada e a todos os que têm baixado e avaliado os aplicativos produzidos no projeto. Para as melhorias futuras e avaliações no aplicativo Pixel e em outros aplicativos deste projeto, agradecemos desde já ao apoio financeiro da Chamada n. 03/2020 Produtividade em Pesquisa PROPESQ/PRPG/UFPB, onde este projeto está inscrito com o código PVP13499-2020 no SIGAA.

\section{REFERÊNCIAS}

[1] Tim Bell, Ian H Witten, and Mike Fellows. 2011. Computer Science UnpluggedEnsinando Ciência da Computação sem o uso do computador. Tradução coordenada por Luciano Porto Barreto (2011), 3-45.

[2] Ivonildo Pereira Gomes Neto. 2019. Adaptação de Usabilidade no Aplicativo Computação Plugada com Foco em Crianças. Trabalho de Conclusão de Curso (Licenciatura em Ciência da Computação) - UFPB.

[3] Matheus Oliveira. 2019. Avaliando um Aplicativo Android para Apoiar a Aplicação de Exercícios de Computação Desplugada. Trabalho de Conclusão de Curso (Licenciatura em Ciência da Computação) - UFPB.

[4] Matheus Oliveira, Ayla Dantas, and Ivonildo Neto. 2019. Computação Plugada: Um Aplicativo Android Para Apoiar a Aplicação de Exercícios de Computação Desplugada. In Anais do XXVII Workshop sobre Educação em Computação. SBC, 493-502.

[5] Jeannette M Wing. 2014. Computational thinking benefits society. 40th Anniversary Blog of Social Issues in Computing 2014 (2014), 26. 